\title{
Oral health-related quality of life as a predictor of alcohol and cigarette consumption in adolescents
}

\author{
Bruna BRONDANI ${ }^{(a)}$ iD \\ Camila Silveira SFREDDO(b) \\ Jessica Klöckner KNORST(a) \\ Yassmín Hêllwaht RAMADAN(a) iD \\ Fernanda Ruffo ORTIZ(a) ID \\ Thiago Machado ARDENGHI(a) \\ (a) Universidade Federal de Santa Maria - \\ UFSM, School of Dentistry, Department of \\ Stomatology, Santa Maria, RS, Brazil. \\ (b) Universidade Franciscana - UFN, School of \\ Dentistry, Santa Maria, RS, Brazil.
}

Declaration of Interests: The authors certify that they have no commercial or associative interest that represents a conflict of interest in connection with the manuscript.

Corresponding Author:

Thiago Machado Ardenghi

E-mail: thiardenghi@hotmail.com

Submitted: January 25, 2021

Accepted for publication: October 11, 2021

Last revision: November 14, 2021

\begin{abstract}
This study evaluated the influence of Oral Health-Related Quality of Life (OHRQoL) on the consumption of alcohol and cigarette use in adolescents. This prospective cohort began in 2012 (T1) with an initial random sample of 1134 12-year-old adolescents followed for 6 years in Santa Maria, southern Brazil. The present study comprised data from the two cohort reassessments that took place in 2014 (T2) and 2018 (T3). OHRQoL was measured with the Brazilian short version of the Child Perceptions Questionnaire (CPQ11-14) at T2. Socioeconomic, demographic, and oral health measures were also collected during this period. Alcohol and cigarette consumption (regular use) in the past 30 days was evaluated at T3 through questions in the of the National School Health Survey (PeNSE) questionnaire. A multilevel Poisson regression model was used to evaluate the influence of predictor variables on substance use. Of the 770 adolescents at T2, 575 and 576 adolescents were reassessed at T3 for alcohol and cigarette consumption, respectively. Adolescents with higher overall CPQ11-14 scores were at higher risk for regular consumption of alcohol (IRR 1.01; 95\% CI 1.01-1.02) and cigarette (IRR 1.04; 95\% CI 1.03-1.05). Non-white adolescents with low socioeconomic status, untreated dental caries, and who had not been to the dentist (last 6 months) were also associated with increased regular consumption of licit substances. Adolescents with worse OHRQoL presented a higher consumption of alcohol and cigarette. These findings are useful for planning public health strategies to improve adolescent OHRQoL and reduce the harmful substance use.
\end{abstract}

Keywords: Adolescent; Alcohol Drinking; Cigarette Smoking; Oral Health; Quality of Life.

\section{Introduction}

Licit drugs are the most widely used harmful substances in the world, represented by cigarettes and alcohol, and are one of the greatest public health problems in both low- and high-income countries. ${ }^{1}$ This consumption begins in adolescence, a transitional phase that favors the emergence of vulnerable and susceptible behaviors that can lead to the adoption of habits that are harmful to health. ${ }^{1}$ In Brazil, the prevalence of alcohol and cigarette use among adolescents aged 10-19 years reaches 
$34.9 \%$ and $9.3 \%$, respectively. ${ }^{2}$ Consequently, the use of these substances promotes social and financial damage to society, as well as a negative impact on the general and oral health of users. ${ }^{1}$

Sociocultural, environmental, and psychological factors have been identified as key theoretical pathways for the explanation of licit drug use in adolescence. ${ }^{3}$ Psychosocial factors are also considered to be additional determinants of harmful substance use, which receive great attention due to their relationship with health risk behaviors. ${ }^{4}$ Psychosocial factors are guided by psychosocial theory, which is concerned with the ways in which individuals perceive social inequities and the effects of these perceptions on health. Among psychosocial variables, the quality of life of an adolescent is associated with resilience to life's challenges and the establishment of health-related behaviors and healthy interpersonal relationships. ${ }^{5}$

Health-Related Quality of Life (HRQoL) represents the individual's perception of the impact of adversities on health in various domains of life, including physical, mental, and social. ${ }^{6}$ Recent results have demonstrated that HRQoL has a predictive role in social relationships, adoption of addictions, and use of health services. ${ }^{7}$ In addition, HRQoL prospectively predicts sustained remission of illicit drug use. These findings suggest that the relationship between HRQoL satisfaction and substance misuse is likely reciprocal and unidirectional, that is, substance use affects HRQoL and HRQoL affects substance use. ${ }^{8}$

Furthermore, Oral Health-Related Quality of Life (OHRQoL), a part of HRQoL that refers to the impact of oral disorders on an individual's normal functioning, has also been explored in the same field. ${ }^{9}$ Previous results have demonstrated that impaired OHRQoL is associated with behavioral indicators, such as use of dental services in children. ${ }^{10}$ It has also been observed that individuals with worse OHRQoL show an impaired subjective well-being, which may adversely affect behavioral habits. ${ }^{11}$ In this sense, we believe that the possible association between OHRQoL and substance use is due to the physical and/or psychological distress that oral disorders can cause, impacting the individuals' OHRQoL. ${ }^{12}$ This condition can promote stress and anxiety and encourage unhealthy behaviors, such as alcohol and cigarette use. ${ }^{13}$

To our knowledge, no previous study has evaluated the effect of a subjective variable related to dental clinical conditions on the consumption of harmful substances. This relationship is particularly important, especially in adolescents, as the consumption of these substances can lead to chemical dependency and health-related problems at this stage and in adulthood, such as the occurrence of noncommunicable and infectious diseases, mental disorders, injuries, violence, homicides, and poisoning. ${ }^{1}$ Therefore, this study aimed to evaluate the influence of OHRQoL on alcohol and cigarette use among adolescents. We hypothesized that adolescents with worse OHRQoL are more likely to consume harmful substances.

\section{Methodology}

This study is reported according to STROBE (Strengthening the Reporting of Observational Studies in Epidemiology) guidelines. ${ }^{14}$

\section{Ethical issues}

The study protocol was approved by the Ethics Committee on Research of the Federal University of Santa Maria (UFSM) (CAEE: 66553117.4.0000.5346). A written informed consent form was obtained from all adolescents and their parents or legal guardians.

\section{Study setting and sample}

This prospective cohort study with 6 years of follow-up began in 2012 (T1) with an initial sample of 1,134 12-year-old schoolchildren enrolled in public schools in Santa Maria, a city in southern Brazil. At that time, Santa Maria had about 261,031 inhabitants, including 3,817 12-year-old students, $85 \%$ of whom were enrolled in public schools. ${ }^{15}$ The sample was obtained through a two-stage sampling procedure. The primary sampling units were all public schools in the city: a total of 20 out of 39 schools were randomly selected, with a probability proportional to the school size. The secondary sampling units included all 12-year-old students enrolled in the 20 selected schools, who were invited to take part in the study. Only adolescents who consented and 
whose parents/guardians signed the consent form were included in the study $(n=1,134)$. Further details regarding the methodological aspects are published elsewhere. ${ }^{16}$ Participants were reassessed in two subsequent moments, in 2014 (T2) and 2018 (T3).

This research used data collected in the T2 and T3 follow-up assessments, totaling 4 years of follow-up. The sample size was calculated considering a prevalence of impact on OHRQoL of $46 \%$ in the non-exposed group (substance non-users) and 74\% in the exposed group (substance users), confidence level of $95 \%$, exposed/unexposed ratio of 2:1, design effect of 1.6, and statistical power of $90 \%{ }^{17}$ Adding $30 \%$ for eventual losses resulted in a minimum sample of 325 adolescents. As this study is part of a cohort that evaluates other conditions, a larger sample than required was included.

\section{Follow-up assessment}

All adolescents evaluated in 2012 were considered eligible and invited to participate in the second and third phases of follow-up. Data was collected from 770 individuals reassessed between September 2014 and May 2015, and 768 individuals reassessed between October 2017 and October 2018. Socioeconomic, demographic, and subjective variables were collected through face-to-face interviews with structured questionnaires. Pre-trained and calibrated examiners conducted clinical examinations.

Three methods were employed as search strategies. First, telephone calls were made to resume contact with participants and invite them to attend the pediatric dentistry clinic of the UFSM. A second alternative was to obtain lists of students enrolled in public schools in the city and review them in a school setting. Finally, researchers went to the home addresses of participants to locate individuals not found in the other two alternatives, and examined them in their home environment.

\section{Alcohol and cigarette (outcomes)}

The consumption of alcohol and cigarette (considered licit substances for people over 18 years of age in Brazil) by adolescents was collected at T3, through a self-applied questionnaire including questions present in the National School Health Survey (PeNSE) questionnaire. ${ }^{18}$ PeNSE is a sample survey widely applied in the country and carried out by the Brazilian Institute of Geography and Statistics (IBGE). Further details on the PeNSE survey are published elsewhere. ${ }^{18}$

Regular consumption of alcohol and cigarette was measured numerically by the mean of days of consumption through the following questions: a) Regular cigarette use - "In the past month, on how many days did you smoke cigarettes?"; b) Regular alcoholic beverage use - "In the past month, on how many days did you drink at least one dose of alcohol?". ${ }^{18}$ In the analysis, regular cigarette and alcohol consumption were used as quantitative variables. According to the PeNSE criteria, one dose of alcohol corresponds to a glass of beer, a glass of wine, and a serving of cachaça (typical Brazilian drink), or vodka, or whiskey, etc. ${ }^{18}$ Substance use in the past 30 days among adolescents is a standard measure to indicate current consumption. These questions were applied to test internal consistency in 25 adolescents attending a dental clinic at UFSM. They presented similar socioeconomic profiles to the sample of this research, but were not participants in the cohort study. The Cronbach's $\alpha$ was 0.84 .

\section{Oral health-related quality of life}

At T2, the adolescents answered the Brazilian short version of the Child Perceptions Questionnaire for 11- to 14-year-old children (CPQ11-14) through face-to-face interviews with previously trained interviewers. ${ }^{19}$ This short form contains 16 questions on the frequency of events in four domains: oral symptoms (OS), functional limitation (FL), emotional well-being (EW), and social well-being (SW). Each question measures the frequency of events related to teeth, lips, and jaws in the past 3 months and it has five possible answers on a Likert scale ranging from 0 to 4: "Never" = 0; "Once or twice" = 1; "Sometimes" = 2; "Often" = 3; "Every day/almost every day" $=4$. The final score is calculated by the sum of all scores for each domain, and it can range from 0 to 64 . Higher scores represent worse OHRQoL.

\section{Covariates}

All covariates were measured at T2. A structured questionnaire, applied to parents or guardians, 
provided information about sex, age, race, household income, and adolescent oral health measures. The questionnaire was answered in person if the participant was evaluated in a clinical setting or at home. If a participant was evaluated in a school, the parent/guardian answered the questionnaire by telephone. Race was classified based on the criteria of the IBGE and dichotomized as "White" and "Non-White". ${ }^{15}$ Household income was recorded in Brazilian reals ( $\mathrm{R} \$$ - official Brazilian currency) for all individuals living in the house in the last month and converted to terciles. Oral health measures included dental visits in the previous 6 months and adolescents' self-perception of gingival bleeding.

Clinical examinations were conducted by 4 trained and calibrated examiners, according to international criteria standardized by the World Health Organization $(\mathrm{WHO})^{20}$ under natural light using a plane dental mirror and WHO periodontal probe (CPI; "ball point"), in a private setting. Untreated dental caries (corresponding to a non-zero D component in the Decayed, Missing, and Filled teeth index - DMFT) was measured according to the WHO criteria. ${ }^{20} \mathrm{Kappa}$ statistics (inter and intra-examiner) for dental caries measures were higher than 0.7.

\section{Data analyses}

Data analysis was performed with STATA 14 (StataCorp. 2014. Stata Statistical Software: Release 14.1. College Station, TX: StataCorp LP). The outcomes were regular alcohol and cigarette consumption, and were analyzed as continuous variables. All descriptive analyses considered the sampling weight, using the "svy" commands in Stata for complex data samples.

Multilevel Poisson regression models were used to estimate the association between outcomes and explanatory variables, according to a previous theoretical model..$^{21}$ In the multilevel assessment, adolescents (first level) were nested in their schools (second level). Multilevel models allow estimating the incidence rate ratio (IRR) and its 95\% CI. In this approach, variables with a p-value $<0.25$ in the unadjusted model were included in the adjusted model through a stepwise forward procedure. In the final model, all variables with a $\mathrm{p}$-value $<0.05$ were considered statistically associated with alcohol and cigarette use. The multilevel model used the scheme of fixed effect with a random intercept. The goodness of fit of the model was evaluated using the deviance ( $-2 \log$ likelihood) and the median incidence rate ratio (MIRR). Significant changes in the fitting of the models were assessed using the likelihood ratio test.

\section{Results}

Of the 1,134 adolescents assessed at baseline, 770 (67.9\% retention rate) and 768 (67.7\% retention rate) participants were re-evaluated at T2 and T3, respectively. However, only those participants who were evaluated in both $\mathrm{T} 2$ and $\mathrm{T} 3$ were considered in this study (4 years of follow-up). Therefore, the final sample was 575 adolescents for the alcohol beverage outcome and 576 adolescents for the cigarette-smoking outcome. In the null model, it was observed that schools influenced the consumption of harmful substances, according to the obtained p-value (alcohol: $p<0.05$; cigarette: $p=0.001$ ). The fixed intercept for the variables alcohol and cigarette use in the null model was 2.70 and 1.75 , while the random intercept (deviance) was 1.38 and 0.11 for the respective variables. Poisson multilevel modeling showed a significant effect of contextual level for alcohol and cigarette consumption, respectively (MIRR $=1.333$ and MIRR =1.980). The mean age of adolescents was 14.3 years (Standard Deviation [SD] 0.7) at T2 and 17.5 years (SD 0.6) at T3. Sixty percent and $16.2 \%$ of adolescents were regular users of alcoholic beverages and cigarettes, respectively. At T2, the OS, FL, EW, and SW domains that make up the CPQ11-14 had the following means: 3.36 (SD 2.36), 2.44 (SD 2.52), 2.19 (SD 3.20), and 1.37 (SD 1.97). Reasons for dropouts are presented in Figure. There were no statistical differences between participants and non-participants in T2 and T3 ( $p>0.05)$ (data not shown).

Table 1 shows regular alcohol and cigarette consumption according to predictor variables measured at $\mathrm{T} 2$. The adolescents were predominantly girls, white, and lived in households with income less than $\mathrm{R} \$ 880.00$. The prevalence of untreated dental caries was approximately $40 \%$ for both outcomes. The mean overall CPQ11-14 score was 9.28 (Standard 


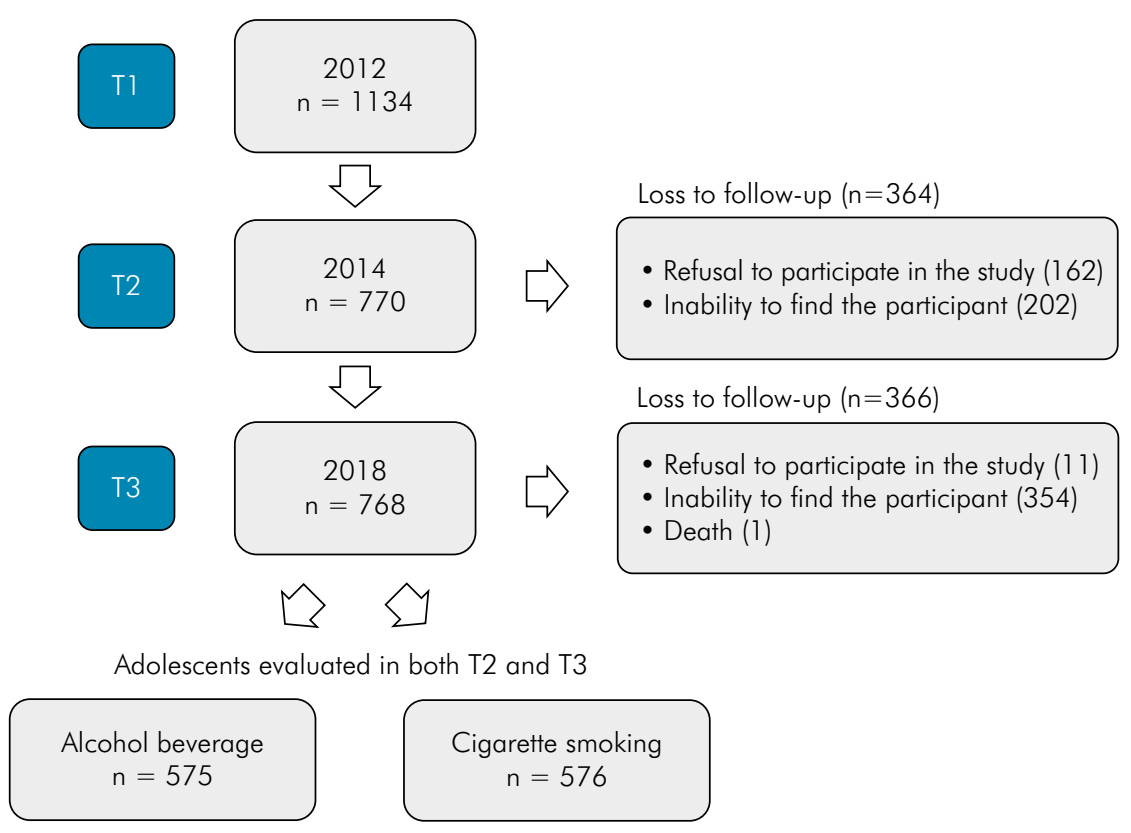

Figure. Flowchart of participants in the 3 different phases of cohort follow-up.

Error [SE] 0.3) for alcohol consumption and 9.24 (SE $0.3)$ for cigarette consumption. It was observed that adolescents with a higher mean of regular alcohol and cigarette consumption were boys, non-white, and those belonging to the lowest household income tercile. Consumption was also higher in adolescents with worse OHRQoL and untreated dental caries.

Table 2 shows the multilevel Poisson analysis for regular consumption of alcohol. After adjustment, higher overall CPQ11-14 scores were associated with consumption of alcohol (IRR 1.01; 95\% CI 1.01-1.02). Regular consumption was also higher among boys, non-white, and those belonging to families with lower income (lowest tercile). Not visiting the dentist in the past 6 months was also associated with higher consumption of alcohol beverage. In addition, lack of perception of gingival bleeding was a protective variable against alcohol consumption.

Table 3 shows the multilevel Poisson analysis for regular cigarette smoking. After adjustment, adolescents who had a worse OHRQoL showed higher regular cigarette use (IRR 1.03; 95\% CI 1.02-1.04). Use was also higher in boys and adolescents with poorer socioeconomic status. The presence of untreated dental caries and absence of dental visits in the past 6 months were considered predictors of cigarette use.

\section{Discussion}

This longitudinal study confirmed the hypothesis that individuals with worse OHRQoL have higher regular alcohol and cigarette consumption. Findings also suggest that demographic (sex and race), socioeconomic (household income), and oral health measures (dental visits, untreated dental caries, and self-perception of gingival bleeding) are related to regular consumption of licit substances. To the best of our knowledge, there are few studies evaluating the influence of OHRQoL on behavioral outcomes, ${ }^{10,11}$ and there are no studies evaluating its relationship with consumption of licit drugs, especially in a sample of adolescents.

The psychosocial theory supports the relationship between OHRQoL and consumption of harmful substances, as it supports the idea that psychological growth occurs through stages and phases, depending on the interaction between the individual and his or hers context. ${ }^{4}$ Previous studies have shown that feelings of subordination or inferiority encourage the development of stressful responses, which can have consequences for physical and mental health. ${ }^{22}$ Psychosocial factors, such as OHRQoL, also influence the individual's perception of their position in society, 
Table 1. Sample characteristics and distribution of regular alcohol and cigarette consumption according to demographic, socioeconomic, and oral health variables at T2.

\begin{tabular}{|c|c|c|c|c|}
\hline \multirow{3}{*}{ Variables $(\mathrm{T} 2)^{\mathrm{a}}$} & \multicolumn{2}{|c|}{ Alcohol use (T3) ${ }^{\mathrm{b}}$} & \multicolumn{2}{|c|}{ Cigarette use (T3) ${ }^{\mathrm{b}}$} \\
\hline & \multicolumn{2}{|c|}{$(n=575)$} & \multicolumn{2}{|c|}{$(n=576)$} \\
\hline & n (\%) & Mean $(\mathrm{SE})^{\mathrm{c}}$ & n (\%) & Mean $(\mathrm{SE})^{\mathrm{c}}$ \\
\hline \multicolumn{5}{|l|}{ Demographic variables } \\
\hline \multicolumn{5}{|l|}{ Sex } \\
\hline Girls & $316(53.4)$ & $2.5(0.3)$ & $318(53.5)$ & $1.5(0.4)$ \\
\hline Boys & $259(46.6)$ & $2.8(0.1)$ & $258(46.5)$ & $2.0(0.4)$ \\
\hline \multicolumn{5}{|l|}{ Race } \\
\hline White & $446(79.9)$ & $2.5(0.1)$ & $448(80)$ & $1.7(0.3)$ \\
\hline Non-white & $121(20.1)$ & $3.2(0.8)$ & $120(20)$ & $2.0(0.6)$ \\
\hline \multicolumn{5}{|l|}{ Socioeconomic variables } \\
\hline \multicolumn{5}{|l|}{ Household income in $R \$^{d}$} \\
\hline Highest ( $3^{\text {rd }}$ tercil) & $144(36.5)$ & $2.3(0.3)$ & $145(36.7)$ & $0.7(0.3)$ \\
\hline Medium (2nd tercil) & $119(27.2)$ & $2.9(0.5)$ & $118(27.1)$ & $1.9(0.5)$ \\
\hline Lowest ( $1^{\text {st }}$ tercil) & $149(36.3)$ & $3.4(0.4)$ & $148(36.2)$ & $2.6(0.7)$ \\
\hline \multicolumn{5}{|l|}{ Oral health measures } \\
\hline \multicolumn{5}{|l|}{ Dental visits (last 6 months) } \\
\hline Yes & $252(54)$ & $2.7(0.3)$ & $252(54)$ & $1.3(0.4)$ \\
\hline No & $219(46)$ & $3.0(0.3)$ & $218(46)$ & $2.0(0.5)$ \\
\hline \multicolumn{5}{|c|}{ Self-perception of gingival bleeding } \\
\hline Yes & $353(61.3)$ & $2.8(0.3)$ & $351(61)$ & $1.8(0.3)$ \\
\hline No & $207(38.7)$ & $2.2(0.3)$ & $210(39)$ & $1.8(0.3)$ \\
\hline \multicolumn{5}{|l|}{ Untreated dental caries } \\
\hline Without & $333(60.8)$ & $2.5(0.2)$ & $335(60.9)$ & $1.4(0.2)$ \\
\hline \multirow[t]{2}{*}{ With } & $226(39.2)$ & $2.7(0.3)$ & $225(39.1)$ & $2.2(0.5)$ \\
\hline & Coefficiente $^{e}$ & Mean $(\mathrm{SE})^{c}$ & Coefficient $^{e}$ & Mean $(\mathrm{SE})^{c}$ \\
\hline OHRQoL (CPQ overall score) & $0.1^{*}$ & $9.28(0.3)$ & 0.05 & $9.24(0.3)$ \\
\hline
\end{tabular}

*Taking into account the sampling weight; ${ }^{\circ} \mathrm{T} 2,2$-year follow-up; ${ }^{\mathrm{b}} \mathrm{T} 3,6$-year follow-up; ${ }^{\mathrm{c} S E}$ : standard error; ${ }^{\mathrm{d}} \mathrm{R} \$$, Real (R $\$ 4.04$ is equivalent to

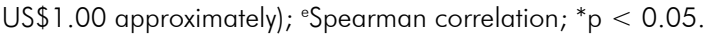

promoting social marginalization and, consequently, antisocial behavior. ${ }^{23}$ Some studies have reported the relationship between psychosocial factors and alcohol and cigarette consumption among adolescents and young adults. ${ }^{4,13}$ It has been argued that individuals with worse psychosocial factors are more likely to use harmful substances. ${ }^{4,13}$ Notwithstanding, results have shown that frustrations in early developmental periods are capable of promoting chemical dependence.

The concept of OHRQoL embraces the biopsychosocial model of health in which symptoms, physical functioning, and emotional and social well-being are considered. ${ }^{24}$ Previous studies have found that emotional well-being and social well-being domains seem to be closely related to substance use in adolescence. ${ }^{25}$ Situations that promote anxiety regarding social situations can exert their influence and make adolescents prone to taking risks. ${ }^{25}$ Also, an interaction between emotions and social contrast with smoking was identified in this study. ${ }^{25}$ Thus, individuals who feel vulnerable to socially stressful stimuli tend to adopt the perceived smoking behaviors of those in their social circle. ${ }^{13}$ Furthermore, economic vulnerability is strongly associated with worse OHRQoL, as the behavioral limitations and lower access to health services of people in a lower socioeconomic conditions are detrimental to the oral health and OHRQoL of individuals. ${ }^{26}$

It is recognized that oral disorders can cause symptoms that affect the perception of oral health and cause a series of daily limitations capable of compromising OHRQoL. ${ }^{12}$ This effect can be 
Table 2. Unadjusted and adjusted association between individual variables at T2 and regular alcohol consumption at T3 determined using multilevel Poisson regression.

\begin{tabular}{|c|c|c|c|c|}
\hline \multirow{2}{*}{ Variables } & IRRa Unadjusted & \multirow{2}{*}{ p-value } & IRRa Adjusted & \multirow{2}{*}{$p$-value } \\
\hline & $(95 \% \mathrm{Cl})^{\mathrm{b}}$ & & $(95 \% \mathrm{Cl})^{\mathrm{b}}$ & \\
\hline \multicolumn{5}{|l|}{ Demographic variables } \\
\hline \multicolumn{5}{|l|}{ Sex } \\
\hline Girls & 1 & 0.019 & 1 & $<0.01$ \\
\hline Boys & $1.13(1.02-1.25)$ & & $1.21(1.07-1.37)$ & \\
\hline \multicolumn{5}{|l|}{ Race } \\
\hline White & 1 & $<0.001$ & 1 & $<0.001$ \\
\hline Non-white & $1.32(1.17-1.49)$ & & $1.46(1.27-1.68)$ & \\
\hline \multicolumn{5}{|l|}{ Socioeconomic variables } \\
\hline Household income in $R \$ c$ & & $<0.001$ & & $<0.001$ \\
\hline Highest (3rd tercil) & 1 & & 1 & \\
\hline Medium (2 $2^{\text {nd }}$ tercil) & $1.38(1.17-1.62)$ & & $1.38(1.17-1.63)$ & \\
\hline Lowest ( $1^{\text {st }}$ tercil) & $1.72(1.48-2.01)$ & & $1.71(1.46-2.02)$ & \\
\hline \multicolumn{5}{|l|}{ Oral health measures } \\
\hline Dental visits (last 6 months) & & $<0.001$ & & $<0.001$ \\
\hline Yes & 1 & & 1 & \\
\hline No & $1.24(1.12-1.39)$ & & $1.34(1.19-1.52)$ & \\
\hline Self-perception of gingival bleeding & & $<0.001$ & & 0.01 \\
\hline Yes & 1 & & 1 & \\
\hline No & $0.80(0.72-0.90)$ & & $0.84(0.73-0.95)$ & \\
\hline OHRQoL (CPQ overall score) & $1.01(1.01-1.02)$ & $<0.001$ & 1.01 (1.01-1.02) & $<0.01$ \\
\hline \multicolumn{5}{|l|}{ Untreated dental caries } \\
\hline Without & 1 & 0.953 & - & - \\
\hline With & $1.01(0.90-1.11)$ & & - & \\
\hline
\end{tabular}

alRR: incidence rate ratio; ${ }^{b} \mathrm{Cl}$ : confidence interval; $C \mathrm{R} \$$, Real (at the time, $\mathrm{R} \$ 4.04$ was equivalent to US\$1.00 approximately).

cumulative over the years, confirming the fact that a negative impact on OHRQoL in a transitional and self-acceptance phase would not disappear in the period considered in this study. ${ }^{27,28}$ This scenario can affect not only the current quality of life, but also long-term physical, psychological, and social development, promoting worse well-being associated with negative feelings. ${ }^{11}$ Furthermore, these feelings may justify the adoption of risky behaviors, such as substances use, since many people find in this habit an escape from the stressful reality they experience. ${ }^{13}$ In this way, although no study has directly explored this relationship, the literature supports the connection between psychosocial variables and the use of harmful substances. ${ }^{4,13}$

The regular consumption of both substances was higher among boys, as previously observed..$^{29}$ During adolescence, males are more prone to substance use, which is closely related to the transmission of family customs and the need to value their self-image. ${ }^{30}$ However, there is no consensus regarding this finding, since other results did not show gender differences or even reported higher use in women. ${ }^{31}$ Non-white adolescents also showed higher cigarette consumption when compared to their counterparts. This is probably related to the fact that non-white individuals still constitute a social minority, have lower socioeconomic and educational conditions, and limited access to health information. ${ }^{32}$

Our findings demonstrated that regular alcohol drinking and cigarette smoking was higher among adolescents belonging to families with lower income. It has been reported that adolescents with a lower socioeconomic status have higher risk for substance use. ${ }^{33}$ Notwithstanding, the risk of starting and persisting in smoking is higher in individuals with low socioeconomic status. Also, socioeconomic barriers limit access to knowledge and facilitate the adoption 
Table 3. Unadjusted and adjusted association between individual variables at T2 and regular cigarette consumption at T3 determined using multilevel Poisson regression.

\begin{tabular}{|c|c|c|c|c|}
\hline \multirow{2}{*}{ Variables } & IRRa Unadjusted & \multirow{2}{*}{$p$-value } & IRRa Adjusted & \multirow{2}{*}{$\mathrm{p}$-value } \\
\hline & $(95 \% \mathrm{Cl})^{\mathrm{b}}$ & & $(95 \% \mathrm{Cl})^{\mathrm{b}}$ & \\
\hline \multicolumn{5}{|l|}{ Demographic variables } \\
\hline \multicolumn{5}{|l|}{ Sex } \\
\hline Girls & 1 & $<0.001$ & 1 & 0.003 \\
\hline Boys & $1.56(1.38-1.76)$ & & $1.25(1.07-1.45)$ & \\
\hline \multicolumn{5}{|l|}{ Race } \\
\hline White & 1 & 0.327 & - & - \\
\hline Non-white & $0.92(0.80-1.07)$ & & - & \\
\hline \multicolumn{5}{|l|}{ Socioeconomic variables } \\
\hline Household income in $R \$ c$ & & $<0.001$ & & $<0.001$ \\
\hline Highest ( $3^{\text {rd }}$ tercil) & 1 & & 1 & \\
\hline Medium (2nd tercil) & $2.05(1.67-2.52)$ & & $1.82(1.48-2.25)$ & \\
\hline Lowest ( $1^{\text {st }}$ tercil) & $2.94(2.40-3.60)$ & & $2.31(1.88-2.86)$ & \\
\hline \multicolumn{5}{|l|}{ Oral health measures } \\
\hline Dental visits (last 6 months) & & $<0.001$ & & $<0.001$ \\
\hline Yes & 1 & & 1 & \\
\hline No & $1.88(1.64-2.17)$ & & $1.76(1.51-2.05)$ & \\
\hline Self-perception of gingival bleeding & & 0.223 & & 0.052 \\
\hline Yes & 1 & & 1 & \\
\hline No & $1.07(0.95-1.21)$ & & $1.16(0.99-1.36)$ & \\
\hline OHRQoL (CPQ overall score) & $1.01(1.01-1.02)$ & $<0.001$ & $1.03(1.02-1.04)$ & $<0.001$ \\
\hline \multicolumn{5}{|l|}{ Untreated dental caries } \\
\hline Without & 1 & $<0.001$ & 1 & 0.008 \\
\hline With & $1.37(1.21-1.54)$ & & $1.21(1.05-1.40)$ & \\
\hline
\end{tabular}

alRR: incidence rate ratio; ${ }^{b} \mathrm{Cl}$ : confidence interval; $c R \$$, Real (at the time, $\mathrm{R} \$ 4.04$ was equivalent to US\$1.00 approximately).

of unhealthy habits. ${ }^{34}$ However, such findings have not been consistent across studies, probably due to differences in the methodology employed, cultural factors, geographic characteristics, and socioeconomic indicators, which limit the comparison of findings.

Clinical oral measures were also associated with outcomes. Adolescents with higher perception of gingival bleeding presented a higher consumption of alcohol. On the other hand, those with dental caries had a higher consumption of cigarettes. Previous authors have reported the association of clinical status and OHRQoL in adolescents, ${ }^{12}$ justified by the physical and psychological impact of these conditions on this age group. The presence of pain/discomfort and food impaction in teeth, as well as aesthetic impairment due to bleeding gums, lead to experience a worse perception of oral health and self-esteem in affected individuals. Furthermore, previous results have shown that adolescents with gingival bleeding were more likely to be verbally bullied than their peers, showing another psychosocial face that contributes to feelings of inferiority, ${ }^{35}$ which favors the adoption of habits that are detrimental to health. ${ }^{10}$ Individuals with worse oral health conditions are also more likely to have poorer overall health and harmful health behaviors, since an unfavorable socioeconomic environment with fewer biological resources reduces the chances of adopting healthy habits, which in turn can increase the risk of oral diseases and facilitate the use of alcohol and cigarettes. ${ }^{36}$

Although we investigated two outcomes that are considered legal substances in society, the motivation for their use is not the same across different subpopulations, leading to the different prevalence of use of the two substances. The likely explanation for high alcohol consumption is that drinking is seen as a ritual of sociability that represents the introduction of the adolescent in a friendship group. ${ }^{37}$ 
Besides, drinking is also associated with a moment of relaxation and pleasure. ${ }^{37}$ On the other hand, one of the main reasons why adolescents start smoking is curiosity about cigarette. However, there are common determinants of consumption, such as the demographic, socioeconomic, and clinical variables verified in this study. Questions related to substance use among family and friends, school performance, family conflicts, and physical and/or sexual abuse have also been shown to be influential in alcohol and cigarette consumption. ${ }^{3,29}$ The mutual consumption is justified by the fact that individuals develop a greater desire for cigarette smoking when they drink.

The main limitation of this study was that alcohol and cigarette consumption were measured by self-report. This can underestimate the levels of consumption since adolescents may be ashamed or afraid about reporting the truth. However, adolescents were told that their responses would be kept confidential, as they answered these questions individually. Another limitation concerns possible memory bias. However, the prevalence of consumption was consistent with other studies carried out in Brazil, which provide validity to our measurements. ${ }^{2}$ Furthermore, alcohol and cigarette consumption were not measured at study baseline to allow for longitudinal analysis with repeated measures, making it impossible to evaluate whether these values changed over time. In addition, only a few variables were selected and included in the analytical model. Thus, other factors that were not included in the analysis may act as confounding variables between the observed associations. However, variables were selected based on a previously consolidated theoretical model..$^{21}$

Despite these limitations, this study is a prospective cohort with a high retention rate after 4 years of follow-up. This longitudinal assessment provided important information about the influence of OHRQoL on adolescent behavior in a period of transition from adolescence to adulthood. This transitional period contributes to adolescents' susceptibility to adopting health risk behaviors, which can cause current harm, such as disease development, violence, accidents, and poisonings, which can persist into adulthood. ${ }^{1}$ This knowledge has implications for oral health professionals, as it indicates the fundamental role of OHRQoL on adolescent risk behaviors and the importance of providing adequate oral health and OHRQoL. Moreover, this information is also useful in providing additional evidence for planning public health strategies to improve adolescent OHRQoL and reduce use of these substances. Future intervention studies should test the evidence generated in this research, with the aim of improving adolescent behavior through OHRQoL.

\section{Conclusion}

In conclusion, our findings indicated that OHRQoL affects regular consumption of alcohol and cigarette among adolescents. Adolescents with worse OHRQoL presented a higher consumption of both substances. Moreover, demographic, socioeconomic, and clinical conditions were also important predictors of their consumption.

\section{Acknowledgements}

The authors would like to thank the participants and their families for their availability to participate in this study, as well as the collaboration of the schools and the Municipal Education Secretariat of Santa Maria, Brazil. This study was funded by The Conselho Nacional de Desenvolvimento Científico e Tecnológico (process 310482/2015-1) and Fundação de Amparo à Pesquisa do Estado do Rio Grande do Sul (process 2381-2551/14-0). This study was financed in part by the Coordenação de Aperfeiçoamento de Pessoal de Nivel Superior - Brasil (CAPES) - Finance Code 001.

\section{References}

1. World Health Organization. Global status report on alcohol and health 2018. Geneva. World Health Organization; 2018.

2. Barbosa Filho VC, Campos W, Lopes AS. Prevalence of alcohol and tobacco use among Brazilian adolescents: a systematic review. Rev Saúde Pública. 2012 Oct;46(5):901-17. https://doi.org/10.1590/S0034-89102012000500018 
3. Simantov E, Schoen C, Klein JD. Health-compromising behaviors: why do adolescents smoke or drink?: identifying underlying risk and protective factors. Arch Pediatr Adolesc Med. 2000 Oct;154(10):1025-33. https://doi.org/10.1001/archpedi.154.10.1025

4. Donovan JE. Adolescent alcohol initiation: a review of psychosocial risk factors. J Adolesc Health. 2004 Dec;35(6):529.e7-18. https://doi.org/10.1016/i.jadohealth.2004.02.003

5. Kumcagiz H. Quality of life as a predictor of smartphone addiction risk among adolescents. Tech Know Learn. 2019;24(1):117-27. https://doi.org/10.1007/s10758-017-9348-6

6. Testa MA, Simonson DC. Assessment of quality-of-life outcomes. N Engl J Med. 1996 Mar;334(13):835-40. https://doi.org/10.1056/NEJM199603283341306

7. Topolski TD, Patrick DL, Edwards TC, Huebner CE, Connell FA, Mount KK. Quality of life and health-risk behaviors among adolescents. J Adolesc Health. 2001 Dec;29(6):426-35. https://doi.org/10.1016/S1054-139X(01)00305-6

8. Laudet AB, Becker JB, White WL. Don't wanna go through that madness no more: quality of life satisfaction as predictor of sustained remission from illicit drug misuse. Subst Use Misuse. 2009;44(2):227-52. https://doi.org/10.1080/10826080802714462

9. Sischo L, Broder HL. Oral health-related quality of life: what, why, how, and future implications. J Dent Res. 2011 Nov;90(11):1264-70. https://doi.org/10.1177/0022034511399918

10. Goettems ML, Ardenghi TM, Demarco FF, Romano AR, Torriani DD. Children's use of dental services: influence of maternal dental anxiety, attendance pattern, and perception of children's quality of life. Community Dent Oral Epidemiol. 2012 Oct;40(5):451-8. https://doi.org/10.1111/j.1600-0528.2012.00694.x

11. Klotz AL, Tauber B, Schubert AL, Hassel AJ, Schröder J, Wahl HW, et al. Oral health-related quality of life as a predictor of subjective well-being among older adults-A decade-long longitudinal cohort study. Community Dent Oral Epidemiol. 2018 Dec;46(6):631-8. https://doi.org/10.1111/cdoe.12416

12. Feldens CA, Ardenghi TM, Dos Santos Dullius Al, Vargas-Ferreira F, Hernandez PA, Kramer PF. Clarifying the Impact of Untreated and Treated Dental Caries on Oral Health-Related Quality of Life among Adolescents. Caries Res. 2016;50(4):414-21. https://doi.org/10.1159/000447095

13. Kear ME. Psychosocial determinants of cigarette smoking among college students. J Community Health Nurs. 2002;19(4):245-57. https://doi.org/10.1207/S15327655JCHN1904_05

14. Malta M, Cardoso LO, Bastos FI, Magnanini MM, Silva CM. STROBE initiative: guidelines on reporting observational studies. Rev Saude Publica. 2010 Jun;44(3):559-65. https://doi.org/10.1590/S0034-89102010000300021

15. Instituto Brasileiro de Geografia e Estatística - IBGE. Censo 2010: resource document. Rio de Janeiro: Instituto Brasileiro de Geografia e Estatística; 2019 [cited 2019 Jun 20]. Available from: http://www.ibge.gov.br/home/estatistica/populacao/

16. Tomazoni F, Zanatta FB, Tuchtenhagen S, Rosa GN, Del Fabro JP, Ardenghi TM. Association of gingivitis with child oral health-related quality of life. J Periodontol. 2014 Nov;85(11):1557-65. https://doi.org/10.1902/jop.2014.140026

17. Antoniazzi RP, Zanatta FB, Ardenghi TM, Feldens CA. The use of crack and other illicit drugs impacts oral health-related quality of life in Brazilians. Oral Dis. 2018 Apr;24(3):482-8. https://doi.org/10.1111/odi.12786

18. Oliveira MM, Campos MO, Andreazzi MA, Malta DC. [Characteristics of the national adolescent school-based health survey - PeNSE, Brazil]. Epidemiol Serv Saude. 2017 Jul-Sep;26(3):605-16. Portuguese. https://doi.org/10.5123/S1679-49742017000300017

19. Torres CS, Paiva SM, Vale MP, Pordeus IA, Ramos-Jorge ML, Oliveira AC, et al. Psychometric properties of the Brazilian version of the Child Perceptions Questionnaire (CPQ11-14) - short forms. Health Qual Life Outcomes. 2009 May;7(1):43. https://doi.org/10.1186/1477-7525-7-43

20. World Health Organization - WHO. Oral health surveys: basic methods. Geneva: World Health Organization; 1997.

21. Sheiham A, Watt RG. The common risk factor approach: a rational basis for promoting oral health. Community Dent Oral Epidemiol. 2000 Dec;28(6):399-406. https://doi.org/10.1034/j.1600-0528.2000.028006399.x

22. Bartley M. Health inequality: an introduction to concepts, theories and methods. John Wiley \& Sons; 2016.

23. Crinson I, Yuill C. What can alienation theory contribute to an understanding of social inequalities in health? Int J Health Serv. 2008;38(3):455-70. https://doi.org/10.2190/HS.38.3.e

24. Kleinman A. The illness narratives: suffering, healing, and the human condition. New York: Basic; 1988.

25. Reniers RL, Murphy L, Lin A, Bartolomé SP, Wood SJ. Risk perception and risk-taking behaviour during adolescence: the influence of personality and gender. PLoS One. 2016 Apr;11(4):e0153842. https://doi.org/10.1371/journal.pone.0153842

26. Sfreddo CS, Moreira CH, Nicolau B, Ortiz FR, Ardenghi TM. Socioeconomic inequalities in oral health-related quality of life in adolescents: a cohort study. Qual Life Res. 2019 Sep;28(9):2491-500. https://doi.org/10.1007/s11136-019-02229-2

27. Menegazzo GR, Knorst JK, Emmanuelli B, Mendes FM, Ardenghi DM, Ardenghi TM. Effect of routine dental attendance on child oral health-related quality of life: A cohort study. Int J Paediatr Dent. 2020 Jul;30(4):459-67. https://doi.org/10.1111/ipd.12625

28. Knorst JK, Menegazzo GR, Emmanuelli B, Mendes FM, Ardenghi TM. Effect of neighborhood and individual social capital in early childhood on oral health-related quality of life: a 7-year cohort study. Qual Life Res. 2019 Jul;28(7):1773-82. https://doi.org/10.1007/s11136-019-02138-4 
29. Stone AL, Becker LG, Huber AM, Catalano RF. Review of risk and protective factors of substance use and problem use in emerging adulthood. Addict Behav. 2012 Jul;37(7):747-75. https://doi.org/10.1016/i.addbeh.2012.02.014

30. Laukkanen ER, Shemeikka SL, Viinamäki HT, Pölkki PL, Lehtonen JO. Heavy drinking is associated with more severe psychosocial dysfunction among girls than boys in Finland. J Adolesc Health. 2001 Apr;28(4):270-7. https://doi.org/10.1016/S1054-139X(00)00183-X

31. Barreto SM, Giatti L, Casado L, de Moura L, Crespo C, Malta D. Contextual factors associated with smoking among Brazilian adolescents. J Epidemiol Community Health. 2012 Aug;66(8):723-9. https://doi.org/10.1136/jech.2010.122549

32. Stepanikova I, Oates GR. Perceived discrimination and privilege in health care: the role of socioeconomic status and race. Am J Prev Med 2017;52(1S1):S86-S94.

33. Doku D, Koivusilta L, Raisamo S, Rimpelä A. Do socioeconomic differences in tobacco use exist also in developing countries? A study of Ghanaian adolescents. BMC Public Health. 2010 Dec;10(1):758. https://doi.org/10.1186/1471-2458-10-758

34. Nicolau B, Marcenes W, Bartley M, Sheiham A. Associations between socio-economic circumstances at two stages of life and adolescents' oral health status. J Public Health Dent. 2005;65(1):14-20. https://doi.org/10.1111/i.1752-7325.2005.tb02782.x

35. Moraes RB, Knorst JK, Brondani B, Marques BB, Reis MS, Henriqson D, et al. Relationship between gingival bleeding and associated factors with reports of verbal bullying in adolescents. J Periodontol. 2021 Feb;92(2):225-33. https://doi.org/10.1002/JPER.19-0745

36. Akinkugbe AA. Cigarettes, E-cigarettes, and Adolescents' oral health: findings from the population assessment of tobacco and health (PATH) Study. JDR Clin Trans Res. 2019 Jul;4(3):276-83. https://doi.org/10.1177/2380084418806870

37. Kuntsche E, Knibbe R, Gmel G, Engels R. Why do young people drink? A review of drinking motives. Clin Psychol Rev. 2005 Nov;25(7):841-61. https://doi.org/10.1016/i.cpr.2005.06.002 